\title{
Topical Delivery of Niacinamide to Skin Using Hybrid Nanogels Enhances Photoprotection Effect
}

\author{
Renata Basto, Raquel Andrade, Cláudia Nunes, Sofia A. Costa Lima *(D) and Salette Reis \\ Laboratório Associado para a Química Verde (LAQV), REQUIMTE (Rede de Química e Tecnologia), \\ Department of Chemical Sciences, Faculty of Pharmacy, University of Porto, 4050-313 Porto, Portugal; \\ up200800307@icbas.up.pt (R.B.); id9263@alunos.uminho.pt (R.A.); cdnunes@ff.up.pt (C.N.); shreis@ff.up.pt (S.R.) \\ * Correspondence: slima@ff.up.pt; Tel.: +351-220428664
}

check for updates

Citation: Basto, R.; Andrade, R.; Nunes, C.; Lima, S.A.C.; Reis, S. Topical Delivery of Niacinamide to Skin Using Hybrid Nanogels Enhances Photoprotection Effect. Pharmaceutics 2021, 13, 1968. https:// doi.org/10.3390/pharmaceutics 13111968

Academic Editors: Anastasia Detsi and Eleni Kavetsou

Received: 21 October 2021 Accepted: 17 November 2021 Published: 20 November 2021

Publisher's Note: MDPI stays neutral with regard to jurisdictional claims in published maps and institutional affiliations.

Copyright: (c) 2021 by the authors. Licensee MDPI, Basel, Switzerland. This article is an open access article distributed under the terms and conditions of the Creative Commons Attribution (CC BY) license (https:/ / creativecommons.org/licenses/by/ $4.0 /)$.

\begin{abstract}
Niacinamide (NIA) has been widely used in halting the features of ageing by acting as an antioxidant and preventing dehydration. NIA's physicochemical properties suggest difficulties in surpassing the barrier imposed by the stratum corneum layer to reach the target in the skin. To improve cutaneous delivery of NIA, a hybrid nanogel was designed using carrageenan and polyvinylpyrrolidone polymers combined with jojoba oil as a permeation enhancer. Three different types of transethosomes were prepared by the thin-film hydration method, made distinct by the presence of either an edge activator or a permeation enhancer, to allow for a controlled delivery of NIA. Formulations were characterized by measurements of size, polydispersity index, zeta potential, encapsulation efficiency, and loading capacity, and by evaluating their chemical interactions and morphology. Skin permeation assays were performed using Franz diffusion cells. The hybrid hydrogels exhibited robust, porous, and highly aligned macrostructures, and when present, jojoba oil changed their morphology. Skin permeation studies with transethosomes-loaded hydrogels showed that nanogels per se exhibit a more controlled and enhanced permeation, in particular when jojoba oil was present in the transethosomes. These promising nanogels protected the human keratinocytes from UV radiation, and thus can be added to sunscreens or after-sun lotions to improve skin protection.
\end{abstract}

Keywords: in vitro release; jojoba oil; oleic acid; permeation enhancers; transethosomes; tween 80; UV radiation

\section{Introduction}

Bioactive compounds have been delivered across the skin as an alternative to the oral route, which faces substantial challenges regarding the irregular absorption in the gastrointestinal tract, and the low bioavailability for drugs with short plasma half-life times and liver first-pass metabolism [1,2]. Topical drug administration is the term utilized for the application of the drug to specific areas of the skin for a localized effect and which is not intended for systemic distribution [3]. This administration route across the skin can offer many advantages, such as improved patient compliance, the circumvention of liver first-pass metabolism, reduced side effects associated with peaks and troughs in drug plasma concentration, the ease of dose termination when adverse effects occur, sustained drug release, and a high local concentration of the drug rather than systemic levels, thus providing a local effect $[4,5]$.

Niacinamide (NIA), chemically known as pyridine-3-carboxamide, is an amide form of vitamin B3 and a water-soluble molecule with a wide range of mechanisms of action that have been described in the literature [6,7]. This vitamin is not naturally stored in the body, but it can be obtained by the dietary intake of vitamin B3 and tryptophan [8]. NIA is a precursor to energy co-factors in vivo, such as nicotinamide adenine dinucleotide and nicotinamide adenine dinucleotide phosphate $[9,10]$. Since these co-enzymes are involved in many cellular oxidation-reduction reactions, and thus can potentially influence many 
skin mechanisms, the intake of NIA is very important [11]. Yet, the skin provides an effective physical barrier between the external stressors and the inner system, and its barrier function mainly resides in the stratum corneum (SC), which represents the major challenge in the cutaneous administration of molecules highly dependent of their physicochemical properties [12-16]. Although NIA is a small molecule with a size of $122.1 \mathrm{Da}$, it is extremely soluble in water $(212.95 \mathrm{mg} / \mathrm{mL})$ and has a $\log p$ value of -0.37 , which indicates that this bioactive compound alone may not be ideal for topical delivery [17]. Drug delivery systems emerged as a tool to overcome NIA's physicochemical properties that hinder its penetration through the skin. Lee et al. studied the skin permeability and the anti-melanogenesis activity of NIA by incorporating it into flexible liposomes with the edge activator dipotassium glycyrrhizate, proving that the skin permeability of NIA in these flexible liposomes was significantly higher than that of the conventional liposomes [18]. Offerta and co-workers evaluated different strategies to optimize the percutaneous absorption of NIA and soy phytosterols by making use of solid lipid nanoparticles and penetration enhancers such as hydrogenated lecithin [6]. Novel microneedle-like particles were designed to disrupt the skin during the rubbing process and enhance NIA penetration [19]. Skin deposition with a low permeation of NIA will benefit the cutaneous environment, improving hydration and preventing oxidative stress and inflammation. To pursue a novel approach for the topical application of NIA, hybrid nanogels made from a combination of a hybrid hydrogel and transethosomes are explored in this study.

Hydrogels have numerous advantages in drug delivery including increased biocompatibility, tunable biodegradability, low toxicity, proper mechanical strength, and a porous structure adequate to incorporate the active agent [20]. Given the viscoelastic and gelling properties, kappa $(\mathrm{k})$-carrageenan $(\mathrm{k}-\mathrm{CRG})$ is one of the most commercialized seaweedbased polysaccharides for drug delivery and tissue engineering purposes [21-24]. This natural polymer closely mimics the glycosaminoglycan structure, one of the most important constituents of the native tissues' extracellular matrix, as it comprises repeating units of (1,3)-D-glucopyranose and (1,4)-3,6-anhidro- $\alpha$-D-galactopyranose with one sulfate group per disaccharide unit $[25,26]$. Blends between the natural and synthetic polymers lead to hybrid hydrogels, merging the advantageous properties of both. Synthetic polymers' most wanted features are associated with their good mechanical strength, desirable flexibility, chemical inertness, and established structures over natural polymers [27]. Polyvinylpyrrolidone (PVP) is biodegradable, biocompatible, water-soluble, temperature-resistant, and $\mathrm{pH}$ stable with good binding properties for combination with natural polymers [28]. Even so, the hybrid hydrogels may exhibit a restricted mechanical performance and a low capability to achieve high loading and sustained drug release, mainly due to their inherently hydrophilic nature $[29,30]$. Hydrogels containing nanoparticles, also known as nanogels, are promising drug carriers for therapeutic applications and represent a means to overcome these limitations [31-34]. Transethosomes (TEs) merge the advantages of classic ethosomes and transferosomes, with the great capability of becoming deformable and penetrating well into the skin [35-37]. Since the transethosomes contain both the hydrophobic and hydrophilic entities, they can enclose the drug molecules with a wide range of solubility [38], and have edge activators or permeation enhancers (also known as surface active agents) $[35,39]$ in their composition that lead to alterations in the organization of the $S C$ lipids, thereby increasing TEs penetration through the skin [40,41]. Edge activators are membrane softening agents that are capable of changing the membrane's flexibility and enhancing the permeability across the skin [42]. Here, different types of TEs were evaluated upon incorporation in hybrid CRG-PVP hydrogels as topical delivery systems for NIA to improve skin photoprotection.

\section{Materials and Methods}

\subsection{Materials and Instrumentation}

Niacinamide (NIA), k-C RG, polyvinylpyrrolidone (PVP), jojoba oil, tween 80, oleic acid, 4-(2-hydroxyethyl)-1-piperazineethanesulfonic acid (HEPES) powder, k-carrageenan, 
chloroform, jojoba oil, trypsin, and phosphate-buffered saline (PBS) were supplied by Sigma-Aldrich (Alabaster, AL, USA). L- $\alpha$-phosphatidylcholine (EPC) was purchased from Avanti Polar Lipids (Alabaster, AL, USA). Ethanol absolute ( $\geq 99.8 \%$ ) and methanol ( $\geq 99.8 \%$ HPLC grade) were obtained from Fisher Chemical (Thermo Fisher Scientific, Loughborough, UK). Double-deionized water was provided by an ultra-pure water system (Arium Pro, Sartorius AG, Gottingen, Germany). The porcine ears were acquired in a local slaughterhouse (Porto, Portugal). Reagents were weighted in a digital analytical balance Kern ACJ/ACS 80-4 (Kern \& Sohn; Balingen, Germany). The $\mathrm{pH}$ measurements were achieved using a Crison pH meter GLP 22 with a Crison 52-02 tip (Crison; Barcelona, Spain).

\subsection{Methods}

\subsubsection{HPLC Analysis}

NIA analysis was conducted using an HPLC equipped with a reversed-phase monolithic column (Chromolith ${ }^{\circledR} \mathrm{RP}-18 \mathrm{e}, 100 \mathrm{~mm} \times 4.6 \mathrm{~mm}$ i.d., Merck) connected to a Jasco (Easton, PA, USA) HPLC system (pump PU-4180, autosampler AS-4050 and LC-Net II/ADC controller) coupled to a PDA detector (Jasco MD-4010, start wavelength $=200 \mathrm{~nm}$, End Wavelength $=400 \mathrm{~nm}$ ). The data processing was performed by ChromNAV 2.0 HPLC software (Easton, PA, USA). The chromatogram was acquired at a wavelength of $263 \mathrm{~nm}$, and the retention time of NIA was at $4.8 \mathrm{~min}$. The mobile phase was a mixture of water and methanol $(80: 20, v / v)$ and eluted at a flow rate of $1.0 \mathrm{~mL} / \mathrm{min}$. The injection volume was set to $20 \mu \mathrm{L}$ with the column temperature at $30^{\circ} \mathrm{C}$. Prior to use, the mobile phase was degassed in an ultrasonic bath for $30 \mathrm{~min}$. Validation of HPLC method was performed by evaluating linearity, range accuracy, precision, lower limit of quantification (LOQ), and upper limit of detection (LOD) according to established guidelines [43]. The calculated LOD was $0.18 \mu \mathrm{g} / \mathrm{mL}$ and the LOQ was $0.53 \mu \mathrm{g} / \mathrm{mL}$.

\subsubsection{Preparation of Hybrid Hydrogels}

Carrageenan hydrogels were prepared by dissolving the polymer powder in doubledeionized water and heating at $60-70^{\circ} \mathrm{C}$ while stirring in a magnetic stirring plate (IKAWerke, Staufen, Germany) for $30 \mathrm{~min}$ or until a clear solution was obtained. The mixture was allowed to cool slowly during $24 \mathrm{~h}$, until the gelation was complete. In hydrogels containing NIA, the active agent was added $10 \mathrm{~min}$ before the cooling step. Visual appearance, texture, and $\mathrm{pH}$ were evaluated in $24 \mathrm{~h}$.

PVP was the synthetic polymer selected for the preparation of hybrid hydrogels in a ratio of 1:1 $(w / w)$. To study the effect of a permeation enhancer on the ability of CRG hydrogels to permeate NIA through the skin, jojoba oil was selected and added to the CRGPVP mix at the same time interval of both polymers $(0.5 \%, 1 \%, 5 \% w / v)$. Hybrid hydrogels were loaded with NIA $1 \%(w / w)$ regarding the total polymer weight by incorporation at room temperature.

\subsubsection{Preparation of the Transethosomes Formulations}

Transethosomes were prepared by the thin-film hydration method [44]. Three types of TEs were prepared with different surface-active agents (tween 80 , oleic acid, and jojoba oil) and their composition is shown in Table 1. Briefly, EPC and surface-active agents were weighed and dissolved in a mixture of methanol: chloroform $(1: 3, v / v)$. By maintaining pressure under vacuum for $20 \mathrm{~min}$, the organic phase was slowly evaporated at $40^{\circ} \mathrm{C}$ using a rotary evaporator (Buchi Rotavapor R-200, Switzerland) until a thin clear film of lipid mixture was formed. The film was hydrated with water for non-loaded TEs and a water solution containing $30 \mathrm{mg}$ of NIA for loaded-TEs. Formulations were vortexed for $2 \mathrm{~min}$ and, when necessary, the water bath at $45^{\circ} \mathrm{C}$ was used to enhance the detachment of the thin film. The specified volume of ethanol was added, and the formulation was vortexed for $1 \mathrm{~min}$. All prepared dispersions were subjected to ultra-sonication using a probe sonicator (VCX130, Sonics and Material Vibra-CellTM with a CV-18 probe; 115 Newtown, CT, USA) for 5, 10, and 30 s regarding the TE tween 80, TE oleic acid, and TE 
jojoba oil, respectively. All products were kept at $4{ }^{\circ} \mathrm{C}$ until use per se or for incorporation within the CRG-PVP hydrogels.

Table 1. The composition of transethosomes.

\begin{tabular}{cccc}
\hline Ingredient $(\mathbf{m g})$ & TE Tween $\mathbf{8 0}$ & TE Oleic Acid & TE Jojoba Oil \\
\hline EPC & 20 & 20 & 20 \\
Tween 80 & 2 & - & - \\
Oleic Acid & - & - & - \\
Jojoba oil & - & 600 & 600 \\
Ethanol $(\mu \mathrm{L})$ & 600 & 2400 & 2400 \\
Water $(\mu \mathrm{L})$ & 2400 & & \\
\hline
\end{tabular}

\subsubsection{Fourier-Transform Infrared Spectroscopy Evaluation}

About $3 \mathrm{~g}$ of each hydrogel and $2 \mathrm{~mL}$ of each TE were placed into separate $15 \mathrm{~mL}$ falcons and kept overnight in a $-80^{\circ} \mathrm{C}$ freezer (Deep Freezer, GFL ${ }^{\circledR}$, Burgwedel, Germany). Then, the lyophilization proceeded for $72 \mathrm{~h}$ in a freeze drier (LyoQuest -85 plus v.407, Telstar ${ }^{\circledR}$ Life Science Solutions, Terrassa, Spain) at $-80^{\circ} \mathrm{C}$ and $0.40 \mathrm{mbar}$ of pressure. The freeze-dried hydrogels and TEs were analyzed using a FTIR spectrophotometer (Frontier ${ }^{\mathrm{TM}}$, PerkinElmer; Santa Clara, CA, USA) equipped with an attenuated total reflectance device. Obtained spectra were a result of 32 combined scans recorded between 4000 and $600 \mathrm{~cm}^{-1}$, with spectral resolution of $8 \mathrm{~cm}^{-1}$.

\subsubsection{Determination of Loading Capacity}

The ultrafiltration method was utilized for the estimation of drug loading capacity of developed formulations, using an Allegra ${ }^{\circledR} \mathrm{X}-15 \mathrm{R}$ centrifuge (Beckman Coulter, Pasadena, CA, USA). TEs containing NIA were diluted $10 \times$ with methanol and placed in clean Amicon Ultra-4 centrifugal filter units (Merck Millipore Ltd., Carrigtwohill, Co Cork, Ireland). These devices were centrifuged at $2250 \times g$ for approximately $30 \mathrm{~min}$, or until complete separation between the TEs retained in the filter and the solvent phase corresponding to the supernatant. The supernatant representing the unentrapped NIA was rejected and the filter portion of the Amicon tubes were put upside down inside a $50 \mathrm{~mL}$ falcon tube and centrifuged at $2250 \times g$ for $15 \mathrm{~min}$, until the pellet was completely transferred. The sediment was lysed using methanol and water was added to match the ratio of the mobile phase used in the quantification method. The amount of NIA in the pellet was quantified using HPLC analysis, as previously described.

The loading capacity $(L C)$ was calculated by the following formula:

$$
L C(\%)=\frac{\text { Total entrapped drug mass }}{\text { Total TE mass }(\text { lipid }+ \text { surface active agents })} \times 100
$$

\subsubsection{Morphology Evaluation}

Scanning Electron Microscopy

Freeze-dried hydrogels were fixed onto carbon-taped metal pins. Prior analysis by scanning electron microscopy (SEM) using a FEI Quanta 400 FEG ESEM/EDAX Pegasus $\mathrm{X} 4 \mathrm{M}$ at an accelerating voltage of $10 \mathrm{kV}$, the pins were coated with $\mathrm{Au} / \mathrm{Pd}$ by sputtering for $45 \mathrm{~s}$.

\section{Transmission Electron Microscopy}

TEs samples were dropped on a copper grid and left for $1 \mathrm{~min}$. After removing the excess with filter paper, $10 \mu \mathrm{L}$ of $0.75 \%(w / v)$ uranyl acetate was added for $30 \mathrm{~s}$. Then, the TEs morphology was observed by transmission electron microscopy (TEM, Jeol JEM-1400; JEOL, Ltd., Tokyo, Japan) at the accelerating voltage of $60 \mathrm{kV}$. 


\subsubsection{Evaluation of the Physicochemical Properties of Transethosomes}

The physicochemical properties of TEs were assessed with a ZetaPALS zeta potential analyzer (Brookhaven Instruments Corporation; Holtsville, NY, USA). Particle size (PS), polydispersity index $(\mathrm{PDI})$, and zeta potential $(\mathrm{ZP})$ were obtained after $5 \times$ times dilution in water. For particle size measurements, six runs of 2 min were performed at room temperature while for zeta potential six runs of 10 cycles were performed at a scattering angle of $90^{\circ}$.

\subsubsection{Stability Studies}

Storage stability of TEs was evaluated at $4{ }^{\circ} \mathrm{C}$. Samples were withdrawn each week and stability was evaluated by comparing the initial physicochemical parameters with results obtained after storage. After 2 weeks, a significant loss of NIA was detected.

\subsubsection{In Vitro Drug Release Assay}

To evaluate the release of NIA from the NIA-loaded TEs, in vitro release assays were performed using Slide-A-Lyzer ${ }^{\circledR}$ mini dialysis device containing a cellulose membrane. Briefly, $200 \mu \mathrm{L}$ of NIA-loaded TEs (TE tween 80, TE oleic acid and TE jojoba oil TEs) and $250 \mu \mathrm{L}$ of free NIA solution (to a final mass of $50 \mu \mathrm{g}$ ) were pipetted to the devices and placed in beakers containing $20 \mathrm{~mL}$ of HEPES buffer $(\mathrm{pH}=7.4)$. HEPES buffer was kept at $37^{\circ} \mathrm{C}$ for $6 \mathrm{~h}$ under constant stirring, and $1 \mathrm{~mL}$ of medium was taken at timepoints $0.5,1,2$, $3,4,5$ and $6 \mathrm{~h}$. The receptor phase was immediately replenished with an equal volume of fresh receptor medium.

\subsubsection{Skin Permeation Studies}

Skin permeation studies were performed using a Franz diffusion cell system $(9 \mathrm{~mm}$ unjacketed Franz diffusion cell with $5 \mathrm{~mL}$ receptor, O-ring joint, clear glass, clamp, and stir-bar; PermeGear, Inc., Hellertown, PA, USA). The control sample in all experiments was free NIA dissolved in water at the same amount as in all the formulation samples. Skin samples were obtained from pig ear skin of healthy animals at a local slaughterhouse, with no ethical approval needed. The full thickness membranes obtained were stored at $-20{ }^{\circ} \mathrm{C}$ for no longer than two weeks before use. Skin samples were fixed between the donor and the receptor phase, with SC facing upwards into the donor compartment. HEPES buffer ( $\mathrm{pH}$ 7.4) was used as the receptor medium to allow the establishment of physiological mimetic conditions and to sustain permeant solubilization, stirred and thermostated at $37 \pm 1{ }^{\circ} \mathrm{C}$, during all experiments. The sample was applied to the skin surface $\left(0.636 \mathrm{~cm}^{2}\right)$ of the donor, and $1 \mathrm{~mL}$ of the receptor phase was withdrawn through the sampling port of the Franz diffusion cell at defined intervals (1, 3 and $6 \mathrm{~h})$. The receptor phase was immediately replenished with an equal volume of fresh receptor phase. The withdrawn sample was analyzed by HPLC, and the amount of NIA was determined using the previously described conditions. TEs were filtered by the ultrafiltration method before the experiments to separate the non-retained NIA from the loaded-TEs.

To quantify the amount of NIA retained in the skin, skin digestion studies were performed using the Ultra-Turrax at $1200 \mathrm{rpm}$ for $2 \mathrm{~min}$ or until complete destruction of skin samples in $5 \mathrm{~mL}$ of previously described mobile phase. The falcons containing skin samples were placed in an ultrasound bath for $45 \mathrm{~min}$ to help extract the bioactive compound. Following this step, samples were centrifuged for $20 \mathrm{~min}$ at $2250 \times g$ to pellet the skin remains, and the supernatant was collected and placed in a glass tube for evaporation in the rotary vapor. The dried sample was resuspended in $1 \mathrm{~mL}$ of mobile phase with the help of vortex and, when necessary, the water bath was used to enhance the detachment of the thin film. The amount of NIA deposited was quantified by HPLC analysis using the previously described conditions.

Briefly, the apparent permeability $\left(\mathrm{P}_{\mathrm{app}}\right)$ was estimated by the ratio of the sum of the mass of NIA $\left(\mathrm{m}_{\mathrm{a}} / \mathrm{g}\right)$ permeated across membranes and the product of the initial mass in 
donor chamber $\left(\mathrm{m}_{\mathrm{d}} / \mathrm{g}\right)$, the surface area of the skin $\left(\mathrm{A}=0.636 \mathrm{~cm}^{2}\right)$, and the time $(\mathrm{t}=3$, $\mathrm{h}=10,800 \mathrm{~s})$, following the equation:

$$
\mathrm{P}_{\mathrm{app}}(\mathrm{cm} / \mathrm{s})=\frac{\sum \mathrm{m}_{\mathrm{a}}}{\mathrm{m}_{\mathrm{d}} \cdot \mathrm{A} \cdot \mathrm{t}}
$$

\subsubsection{Cellular Viability Assays}

To determine the effect of the unloaded and NIA-loaded hydrogels and nanogels on human keratinocytes (HaCaT cells), a cellular viability assay was performed through assessment of (3-(4,5-dimethylthiazol-2-yl)-2,5-diphenyltetrazolium bromide) tetrazolium reduction assay) metabolic activity (MTT assay). HaCaT cells were cultivated in Dulbecco's modified Eagle medium (DMEM) media supplemented with $10 \%(v / v)$ fetal bovine, $1 \%$ $(v / v)$ streptomycin/penicillin and $1 \%(v / v)$ amphotericin $\mathrm{B}$, and maintained at $37^{\circ} \mathrm{C}$ in a humidified atmosphere of $5 \%(v / v) \mathrm{CO}_{2}$. The cell viability assay was conducted in 96-well plates containing $4 \times 10^{4}$ cells per well. After cell adhesion, the culture medium was replaced by serial dilutions ( 2.5 to $200 \mu \mathrm{M}$ ) of free NIA, hydrogel with and without NIA, and NIA-loaded nanogels. After $24 \mathrm{~h}$ of exposure, the supernatant was removed and the MTT solution $(0.5 \mathrm{mg} / \mathrm{mL})$ added for $2 \mathrm{~h}$ prior replacement with dimethyl sulfoxide. Then, the absorbance was measured at $590 \mathrm{~nm}$ using a Synergy ${ }^{\mathrm{TM}}$ HT Multi-Mode Microplate Reader (BioTek Instruments Inc., Winooski, VT, USA), subtracting the background read at $630 \mathrm{~nm}$. Cells grown only in culture medium and cells treated with Triton ${ }^{\mathrm{TM}} \mathrm{X}-100(1 \%$ $v / v$ ) were used as positive and negative controls, respectively. Results were expressed as a percentage of metabolic activity relative to the values obtained for non-treated cells.

\subsubsection{Ultraviolet B Irradiation-Photoprotective Assay}

HaCaT cells were cultivated at $4 \times 10^{4}$ cells per well in 96-well plates, as previously described. At first, 3 ultraviolet B (UVB) intensities were evaluated (80, 100 and $150 \mathrm{~mJ} / \mathrm{cm}^{2}$ ) to determine the most suitable to reduce cell viability in about $50 \%$. An amount of $80 \mathrm{~mJ} / \mathrm{cm}^{2}$ was selected for the study. Prior to irradiation, cells were treated with $100 \mathrm{mM}$ of NIA as free solution, hydrogel, and nanogel for $4 \mathrm{~h}$. Empty nanogels were used as controls as well as non-irradiated cells. To prevent UVB light absorption by the cell culture medium, the medium was replaced by a thin layer of phosphate buffer solution to cover the cells during irradiation. The irradiation step was conducted using an illuminator system with UVB lamp (TRIWOOD 31/36, Helios Italquartz, Milan, Italy) for $80 \mathrm{~s}$. The intensity of the lamps was verified by an HD 2302.0 radiometer (Delta OHM, Padova, Italy). Then, the cells were incubated in fresh culture media for $24 \mathrm{~h}$ prior to cell viability assessment using MTT assay, as described above.

\subsubsection{Statistical Analysis}

Statistical analysis was performed using the GraphPad Prism software (Version 6.01 for Windows; GraphPad Software Inc., San Diego, CA, USA). The one-way and two-way ANOVA analyses of variance were used to assess the differences between formulations and a value of $p<0.05$ was considered statistically significant.

\section{Results and Discussion}

\subsection{Preparation and Characterization of Niacinamide-Loaded Hybrid Hydrogels}

Aiming to explore the advantages of the natural and synthetic polymer properties, CRG and PVP combinations were pursued. Hybrid hydrogels were prepared from an aqueous polymeric blend consisting of CRG and PVP, both of which are biocompatible polymers. Vegetable oils have been found to be effective penetration enhancers due to the presence of fatty acids; thus, jojoba oil was the natural oil selected for the hydrogel formulation [45]. The effect of the jojoba oil amount in the hybrid hydrogel was evaluated. A quantity of $5 \%(w / v)$ jojoba oil is excessive, leading to the saturation of the mixture and the immiscibility of the oil with the two polymers (Figure S1). So, the assessment proceeds with 0.5 and $1 \%$ of jojoba oil in the hydrogels. 
The SEM images of the CRG-PVP hydrogel matrix with NIA and different ratios of jojoba oil depicting the morphology, distribution, and alignment, are shown in Figure 1 . The CRG-PVP hydrogel presents a three-dimensional robust macrostructure. This observation indicates that a proper combination of CRG and PVP in the hydrogel resulted in the formation of intertwined copolymer hydrogel with a highly linear and aligned network of porous channels. Yacob and collaborators showed that the mixture of CRG and PVP resulted in the formation of a hydrogel with a more regular and porous structure as compared to the structure of the hydrogel of each component alone [46]. Researchers have proven that PVP has strengthened the gel and helped in producing a more regular, compact, and porous network, as CRG alone produced a hydrogel with a non-defined structure. The incorporation of NIA in the CRG-PVP hydrogel does not appear to alter the original aligned alveolar macrostructure. Jojoba oil also does not seem to influence the size and shape of the porous co-polymer hydrogel structure; however, its presence is clear, as it appears to be deposited in the form of a smooth coating, leading to the formation of bubbles on the surface. As the amount of jojoba oil increases in the composition, the oil appears to adopt a patch shape on top of the hydrogel surface. It is noticeable the high affinity that this essential oil has for the polymer matrix, as its accumulation is visible in the area where the alveoli walls merge.
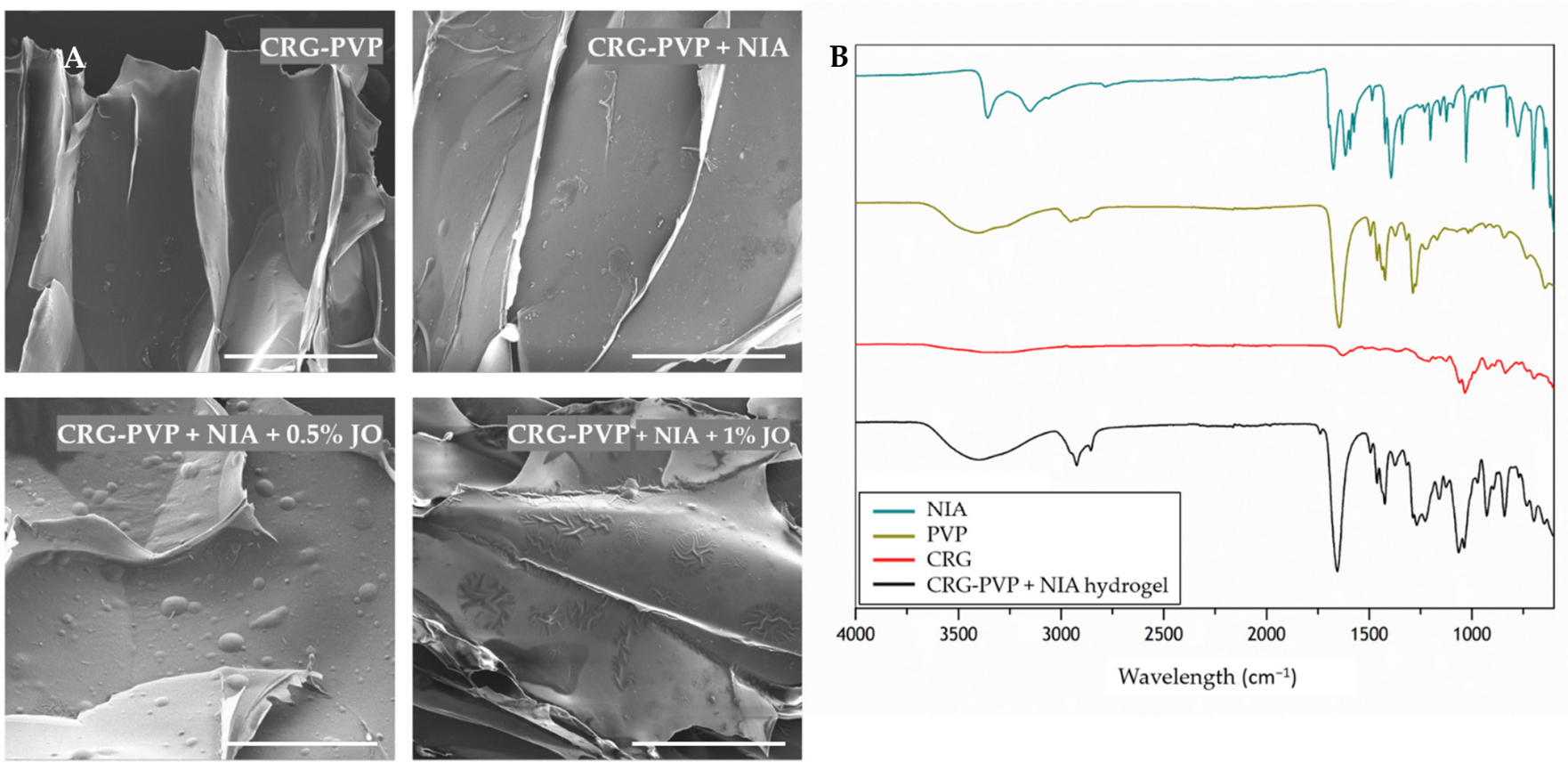

Figure 1. Analysis of the hydrogels morphology (A) and chemical interactions (B). SEM of CRG-PVP hydrogel matrix with NIA and jojoba oil in different amounts (0.5\% and 1\%). Scale bar $200 \mu \mathrm{m}$, amplification of $500 \times$. FTIR spectra of CRG-PVP NIA-loaded hydrogel and all reference compounds in relation to transmittance.

To provide evidence for the interaction of the two polymers and the incorporation of NIA upon the hydrogel production, infrared spectroscopy was performed. The characteristic peaks of the analyzed compounds are detailed in Figure 1, and spectra are given in the range $600-4000 \mathrm{~cm}^{-1}$. From the FTIR data analysis, it is possible to monitor the presence of CRG, PVP and NIA in the hydrogel matrix The typical spectrum of CRG, with the characteristic peaks at 1034, 922 and $836 \mathrm{~cm}^{-1}$ (C-O-C stretching, C-O-C of 3,6-anhydrous galactose and $\mathrm{C}-\mathrm{H}$ rocking, respectively), can be observed [47]. The characteristic peaks of PVP are present at 3404, 2924, 2894 and $1646 \mathrm{~cm}^{-1}$ (C-O stretching, asymmetric $\mathrm{CH}_{2}$ stretching of pyrrole ring, symmetric chain $\mathrm{CH}_{2}$ stretching, and $\mathrm{C}=\mathrm{O}$ stretching, respectively) [48]. In the FTIR spectrum of the CRG-PVP hydrogel, the bands corresponding to the major functional groups belonging to both components can be seen. These results indicate that 
the synthetic polymer PVP is miscible with the natural polymer CRG. It has been shown that the frequency of $\mathrm{C}=\mathrm{O}$ stretch is very sensitive to hydrogen bond formation with water molecules [49]. The pyrrolidone rings in PVP contain a proton accepting carbonyl moiety, whereas CRG presents hydroxyl as a hydrogen donor [49]. Therefore, hydrogen bonding interactions may take place between these two chemical moieties in blends of CRG and PVP. As for NIA, the characteristic peaks are evidenced at 3358-3150, 1674, 1394 and $1028 \mathrm{~cm}^{-1}$ (asymmetric and symmetric $\mathrm{NH}_{2}, \mathrm{C}=\mathrm{O}, \mathrm{C}-\mathrm{N}$, and pyridine stretching, respectively) [50]. The hydrogel is composed of $1 \%(w / w)$ of NIA, thus it is important to note that NIA may have to bind in a higher quantity to be quantified by FTIR analysis. However, it may be that the peak at $1038 \mathrm{~cm}^{-1}$ in the hydrogel spectrum is representative of the NIA characteristic peak at $1028 \mathrm{~cm}^{-1}$, shifted due to vibrational changes from interactions with the polymers. In addition, the peak at $1654 \mathrm{~cm}^{-1}$ in the hydrogel spectrum may be the result of the peak of NIA at $1674 \mathrm{~cm}^{-1}$ masked with the peak of PVP at $1646 \mathrm{~cm}^{-1}$. The chemical nature of the NIA-loaded hydrogel is kept regardless of the different jojoba oil percentage in the matrix, proven by the coincidence of the FTIR curves in the position of the characteristic frequencies (Figure S2).

\subsection{Production and Characterization of Niacinamide-Loaded Transethosomes}

Aiming to explore TEs as a novel approach for the topical application of NIA, three different types of TEs varying in composition due to the presence of either an edge activator, tween 80 (TE tween 80), or a permeation enhancer, oleic acid (TE oleic acid), and jojoba oil (TE jojoba oil), were pursued. While tween 80 and oleic acid have already been studied in compositions for TEs, jojoba oil is an innovative approach and was selected not only for its composition in fatty acids, known for being good permeation enhancers, but also to evaluate its effect on TEs, since its influence was studied in the developed CRG-PVP hydrogels [45].

Empty TEs presented particle sizes between 133 and $320 \mathrm{~nm}$, suitable for topical delivery (Table S1) [51]. Zeta potential values were determined as $-15 \pm 3,-31 \pm 1$ and $-19 \pm 1 \mathrm{mV}$ for TE tween 80, TE oleic acid and TE jojoba oil, respectively, indicating the need to verify the stability during storage. It is well established that when the surface values are equal to or higher than $130 \mathrm{I} \mathrm{mV}$, the nanoparticles have electrostatic stabilization and a low tendency to aggregate [52]. Table 2 shows that the incorporation of NIA in the TEs did not affect the particle size. All the NIA-loaded TEs exhibited a fairly narrow size distribution and good dispersion (PDI value $\leq 0.3$ ). The surface potential varied considerably between $-17 \pm 4 \mathrm{mV}$ for TE tween 80 and $-40 \pm 2 \mathrm{mV}$ for TE oleic acid. These results are expected since tween 80 is a non-ionic surfactant, resulting in lower zeta potential magnitude values [53,54], while the high zeta potential value for oleic acid TEs is due to its negative charge in a water environment. Transethosomes showed loading capacity values ranging from 5.3 to $7.6 \%$, with TE jojoba oil being the most favorable formulation.

Table 2. Characterization of NIA loaded-TEs TE tween 80, II and III.

\begin{tabular}{ccccc}
\hline & PS (nm) & PDI & ZP (mV) & LC (\%) \\
\hline TE tween 80 & $132 \pm 9$ & $0.295 \pm 0.006$ & $-17 \pm 4$ & $5.3 \pm 1.2$ \\
TE oleic acid & $171 \pm 18$ & $0.296 \pm 0.020$ & $-40 \pm 2$ & $6.7 \pm 2.2$ \\
TE jojoba oil & $215 \pm 6$ & $0.232 \pm 0.010$ & $-21 \pm 6$ & $7.6 \pm 2.5$ \\
\hline
\end{tabular}

Each value represents the mean \pm SD of 3 independent measurements $(n=3)$. PS-Particular size; PDI-Polydispersity index; ZP-Zeta potential; LC—Loading capacity.

The morphology of the TEs was assessed by using TEM, and the results are displayed in Figure 2. Overall, all types of TEs exhibited an almost spherical shape, which is the typical liposome structure [55]. As expected, since NIA is a small bioactive compound, its incorporation did not affect the shape nor the size of the nanoparticle. Moreover, in TE oleic acid, the surface active agent may be the compound forming the wire-like structures that can be observed in the lipid bilayer zone. When the aggregations are visible, the 
spherical shape becomes more irregular, which emphasizes the high deformability of the TEs membrane that enables them to adapt its form to the surrounding space [56]. However, it is possible to observe from the images that TE jojoba oil is more predisposed to the formation of aggregates in comparison with the other types.
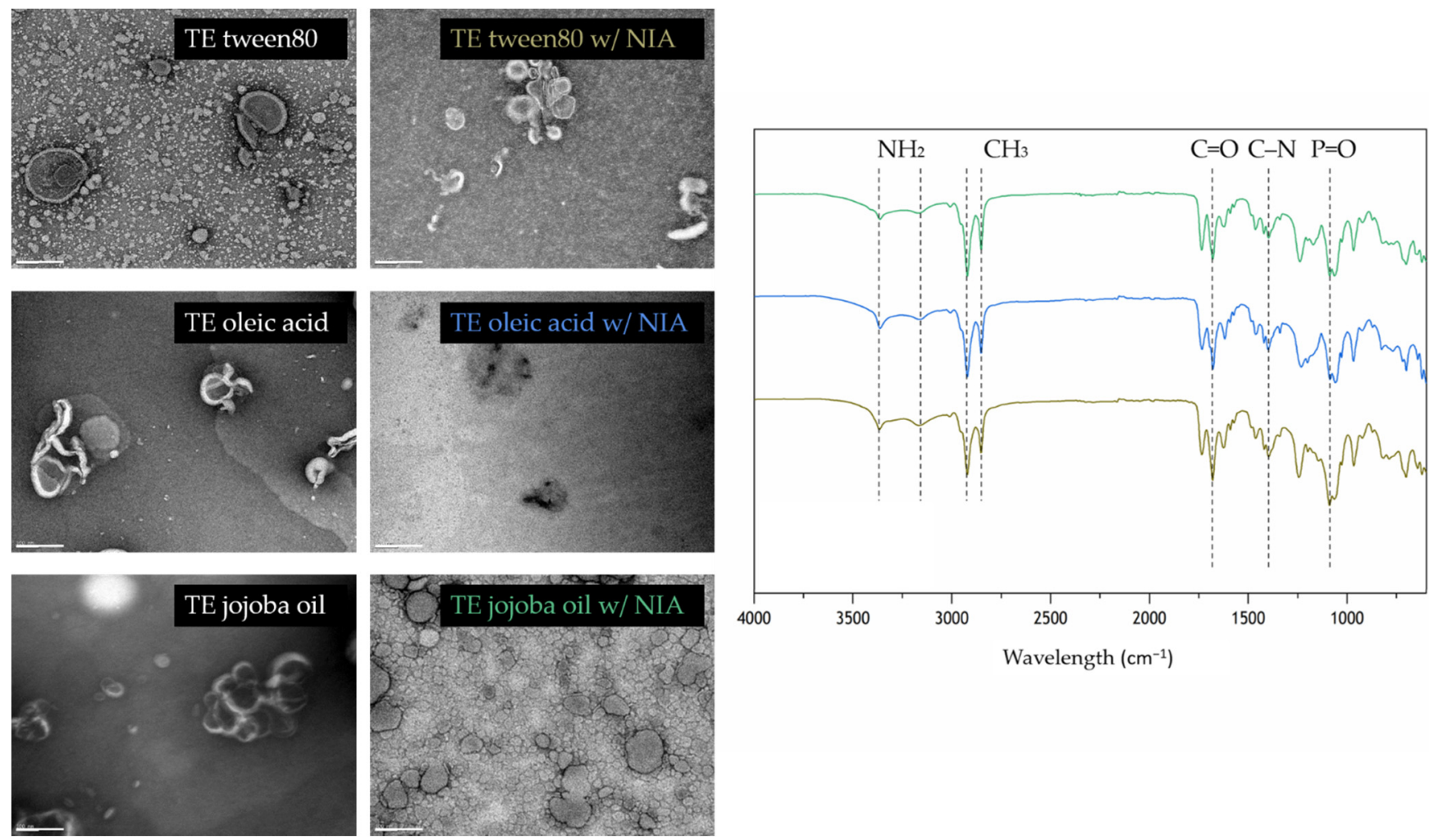

(A)

(B)

Figure 2. Analysis of NIA-loaded and non-loaded TEs morphology (A) and chemical interactions of NIA-loaded TEs (B). TEM of different types of TEs, with and without NIA. Scale bar $200 \mathrm{~nm}$, amplification of 100,000 $\times$. FTIR spectra of TE tween $80 \mathrm{w} /$ NIA (bottom), TE oleic acid w/NIA (middle), and TE jojoba oil w/NIA (top) in relation to transmittance.

The main characteristic molecular vibrations of the EPC transethosomes are kept, regardless of the presence of an edge activator, tween 80 , or a permeation enhancer like oleic acid and jojoba oil (Figure 2). Storage stability was evaluated in terms of particle size, PDI, and zeta potential over 2 weeks at $4{ }^{\circ} \mathrm{C}$ temperature. Collected data remained practically constant (Figure S3); however, variations were observed for $\mathrm{EE} \%$ and $\mathrm{LC} \%$ values after 2 weeks. Overall, the formulations composed of oleic acid are less stable compared to the other two types, given the observed reduction of $\mathrm{EE} \%$ and $\mathrm{LC} \%$ values by half (Figure S4).

The in vitro release of NIA from the different types of TEs was evaluated for $6 \mathrm{~h}$. Figure 3 shows that free NIA has the highest release percentages over time, as expected for a non-encapsulated drug. A burst release is denoted up to $2 \mathrm{~h}$, then reaches stabilization, indicating that after $6 \mathrm{~h}$, all free NIA passed through the membrane. On the other hand, the encapsulated NIA leads to lower release values, highlighting the potential of the sustained release from TEs. TEs tween 80 are slightly faster at releasing NIA compared with the other two types, stabilizing at $50 \%$ of release. Oleic acid TEs and jojoba oil TEs have a similar release profile that stabilizes at $32 \%$ and $34 \%$ of released NIA, respectively. This indicates that tween 80 has a lower retention effect on NIA than oleic acid and jojoba oil. 


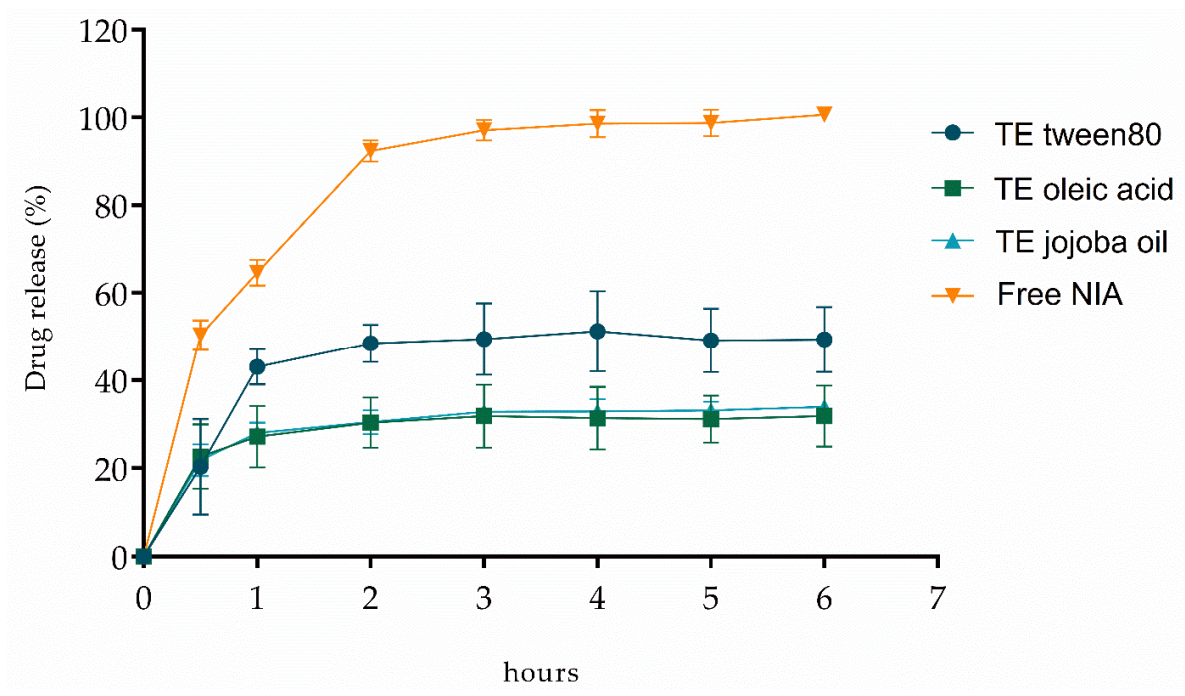

Figure 3. Drug release profile of NIA as free drug and loaded in tween 80, oleic acid, and jojoba oil transethosomes. Each value represents the mean $\pm \mathrm{SD}(n \geq 2)$.

\subsection{Nanogels for Niacinamide Topical Delivery}

The innovative combination of these two drug delivery systems was thought to evaluate the possible permeability enhancements from the hydrogel and/or the transethosome. To determine the skin permeability of the TEs-loaded hydrogels, the CRG-PVP hydrogel $\mathrm{w} / 0.5 \%$ jojoba oil was selected to incorporate the NIA-loaded TEs (tween 80, oleic acid and jojoba oil), forming the nanogels. The choice of the hydrogel was based not only on the respective in vitro permeation assays (Figure S5) but also on the amount of jojoba oil (0.5\%).

From Figure 4, it can be seen that the NIA-loaded hydrogels lead to higher drug permeation compared to the NIA-loaded nanogels. After $1 \mathrm{~h}$, although the differences are not significant, there is a certain prominence of the hydrogel containing TE tween 80 , whose permeation rate slowly increases over time, being surpassed by the permeation capacity of the hydrogel alone. Nevertheless, the NIA-loaded TE tween 80 hydrogel capacity to permeate NIA is always superior to the other two types of TEs incorporated within hydrogel. The combination of hydrogel with TE jojoba oil appears to hamper the ability to permeate NIA, which may be due to the fact that both delivery systems have a certain amount of jojoba oil, resulting in a greater retention of NIA in the upper layers of the skin, which is favorable for skin photoprotection. The skin digestion results obtained are in agreement with the data from the permeation assays, as shown in Table 3. Free NIA showed the lowest deposition value $(6.5 \pm 0.8 \%)$ among all the formulations, leading to the conclusion that the majority of the bioactive remained in the apical compartment. This result emphasizes the expected difficulty of NIA to penetrate and permeate the skin layers, as already reported by other research groups $[57,58]$. A greater retention of NIA in the skin layers can be verified in the case of the nanogels containing TE jojoba oil, which showed a more controlled permeation among the nanogels. 


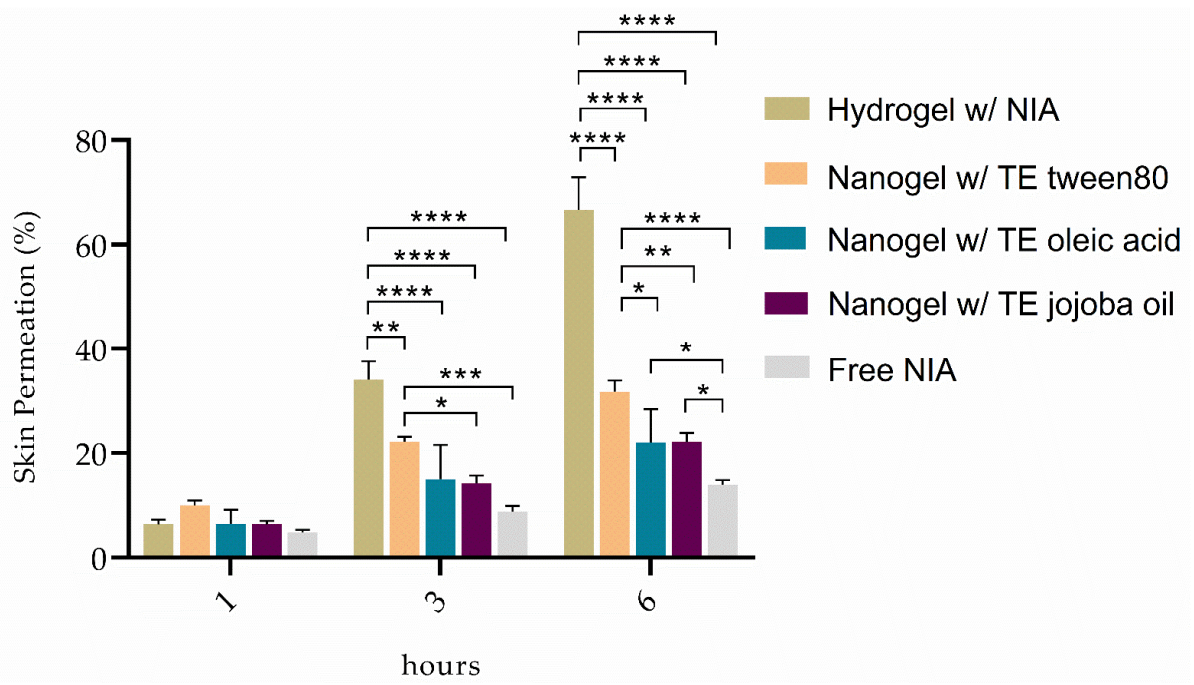

Figure 4. In vitro skin permeation results of free NIA, NIA-loaded hydrogel, and NIA-loaded nanogels (TE tween 80, oleic acid, and jojoba oil) from three independent experiments $(n=3)$. Asterisks indicate statistical significance $\left({ }^{*}, p \leq 0.05 ;{ }^{* *}, p \leq 0.01 ;{ }^{* * *}, p \leq 0.001 ;{ }^{* * * *}, p \leq 0.0001\right)$. No asterisks indicate no statistical significance $(p>0.05)$.

Table 3. Skin deposition of niacinamide.

\begin{tabular}{cc}
\hline & Deposition $\%$ \\
\hline Free NIA & $6.5 \pm 0.8$ \\
NIA-loaded hydrogel & $9.2 \pm 0.6$ \\
NIA-loaded nanogel (TE tween 80) & $10.9 \pm 0.7$ \\
NIA-loaded nanogel (TE oleic acid) & $27.8 \pm 3.5$ \\
NIA-loaded nanogel (TE jojoba oil) & $32.5 \pm 2.3$ \\
\hline
\end{tabular}

Each value represents the mean \pm SD of 4 independent measurements.

Table 4 summarizes the apparent permeability coefficients of the free NIA and NIAloaded hydrogels and nanogels developed in this study, to analyze the apparent permeability rate $\left(\mathrm{P}_{\mathrm{app}}\right)$ of the compound in the receiver compartment, at time point $3 \mathrm{~h}$. As expected, these results are in accordance with the values obtained from the permeation assays performed. Comparing to free NIA data, it is clear that all formulations have a more controlled permeation capacity, as the appearance rate of NIA is less than half in all cases. Among all formulations, it is clear that TEs are more effective at retaining NIA in the skin layers for the intended topical effect. However, due to their viscosity, they cannot be applied alone. Given the consistency and storage stability of the TEs incorporated within the CRG-PVP hydrogels, and the amount of permeated NIA and the $P_{\text {app }}$ values, the combination of the hydrogel with TE jojoba oil is the best option for a local skin action and was further assessed in terms of the photoprotective effect in human keratinocytes.

Table 4. Apparent permeability coefficient of free NIA and NIA-loaded hydrogels and nanogels.

\begin{tabular}{cc}
\hline Composition & $\mathbf{P}_{\mathbf{a p p}}\left(\times \mathbf{1 0}^{-\mathbf{5}} \mathbf{~ \mathbf { m } / \mathbf { s } )}\right.$ \\
\hline Free NIA & $6.49 \pm 0.99$ \\
\hline NIA-loaded hydrogel & $3.01 \pm 0.66$ \\
\hline NIA-loaded nanogel (TE tween 80) & $2.58 \pm 0.87$ \\
NIA-loaded nanogel (TE oleic acid) & $0.90 \pm 0.81$ \\
NIA-loaded nanogel (TE jojoba oil) & $1.17 \pm 0.17$
\end{tabular}

Each value represents the mean \pm SD of 4 independent measurements for hydrogels $(n=4)$ and 3 independent measurements for nanogels $(n=3)$. 
To investigate the biocompatibility of the developed NIA-loaded hydrogel and NIAloaded nanogel (TE jojoba oil), HaCaT cells were first treated with various concentrations of free and loaded NIA $(12.5-200 \mu \mathrm{M})$ for $24 \mathrm{~h}$, and the cell viability was determined. The free and loaded-NIA did not exhibit any significant cytotoxicity and the cell viability was higher than $100 \%$ (Figure 5). Based on these results, the concentration of $100 \mu \mathrm{M}$ was chosen for further cellular studies.

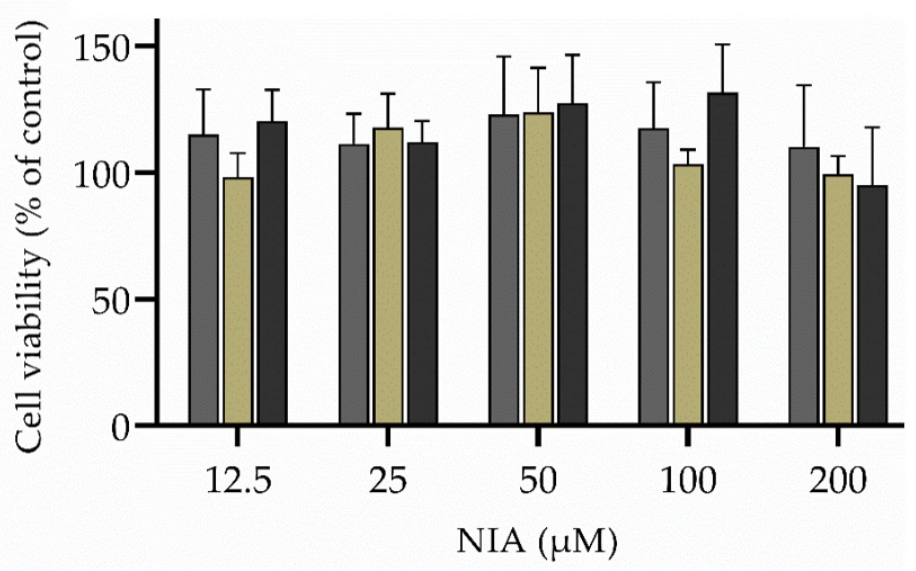

Figure 5. Effects NIA on cell viability in HaCaT keratinocytes. Free NIA (grey bar), NIA-loaded hydrogel (dark yellow), and NIA-loaded nanogel (dark grey) on cell viability in HaCaT keratinocytes. Each value represents the mean $\pm \mathrm{SD}(n \geq 3)$. No asterisks indicate no statistical significance $(p>0.05)$.

Human skin keratinocytes are essential cells in the skin and connective tissue and one of the major targets of UV irradiation [59]. A preliminary study evaluated the effect of different UVB intensities $\left(80,100\right.$ and $\left.150 \mathrm{~mJ} / \mathrm{cm}^{2}\right)$ on $\mathrm{HaCaT}$ cells' death. The intensity of $80 \mathrm{~mJ} / \mathrm{cm}^{2}$ lead to ca. $50 \%$ cell survival and was statistically different from the nonirradiated control group (Figure 6). The free NIA and the NIA-loaded hydrogel did not show significant differences in cell viability in comparison to the irradiated control. However, following treatment with the NIA-loaded nanogel/TE jojoba oil, the cell viability increased up to $80 \%$, highlighting the protection factor of this formulation. These results suggest that the protective effect may be due to the ability of TEs to penetrate skin cells and allow a localized NIA free scavenging activity. A protective effect of NIA on induced oxidative damage in human $\mathrm{HaCaT}$ keratinocytes was associated with the inhibition of ROS generation, lower excessive intracellular $\mathrm{Ca}^{2+}$, balancing membrane potential, suppressing apoptosis, and rescuing cells from lipid oxidation, protein carbonylation, and DNA damage [60]. Rodriguez-Luna and co-authors reported similar UVB protection for HaCaT keratinocytes in the presence of fucoxanthin and rosmarinic acid [61]. NIA is known to repair the oxidative stress and photolesions induced by UV irradiation, as it plays a key role in the cellular energy metabolism by being a precursor of NAD and providing energy to the irradiated cells [62]. In accordance with these properties, the combination of transethosomes containing NIA with a hybrid hydrogel produced a natural tool for the enhanced deposition of NIA in the skin, allowing for an effective photoprotective effect against skin UVB-induced disorders. 


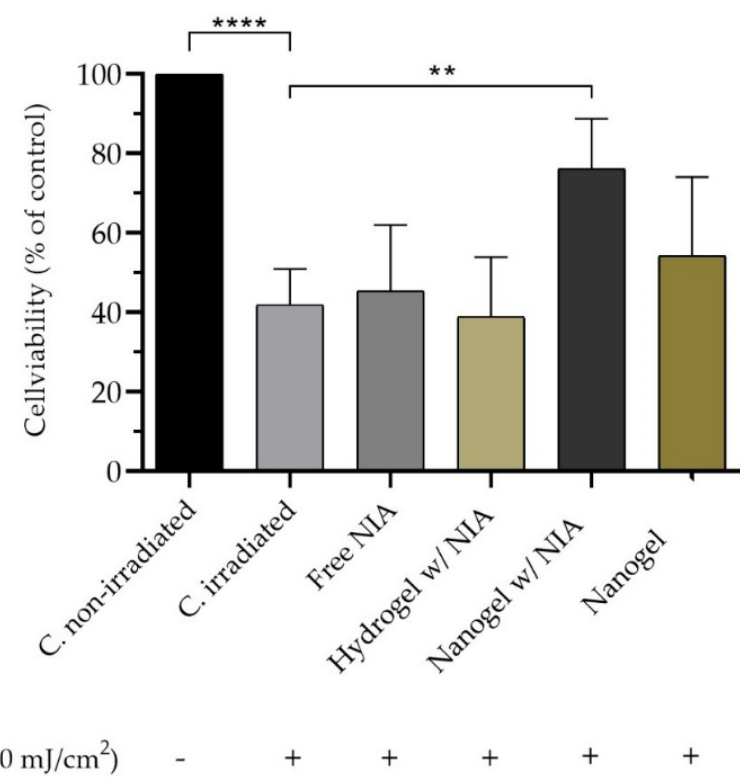

Figure 6. Effects of free NIA and NIA-loaded hydrogel and nanogels on cell viability in UVB $\left(80 \mathrm{~mJ} / \mathrm{cm}^{2}\right)$ irradiated HaCaT keratinocytes at a concentration of $100 \mu \mathrm{M}$. Data are representative of five independent experiments as mean \pm SD. Symbol - represents "absence of" while + means "exposure to". Asterisks indicate statistical significance $\left({ }^{* *}, p \leq 0.01 ; * * *, p \leq 0.0001\right)$. No asterisks indicate no statistical significance $(p>0.05)$.

\section{Conclusions}

NIA formulated for topical application has shown several beneficial results on skin health and protection. In this study, the topical delivery of NIA mediated by CRG-PVP hydrogels resulted in less than $10 \%$ retention in the skin, which is the target tissue for slowing down ageing. As most of the applied NIA in the skin is lost, a combined approach was pursed by taking advantage of the properties of transethosomes. Given the particular composition of TEs, this type of liposome can become deformable and penetrate easily into the skin. Within the three surface active agents examined here in the TEs, the natural permeation enhancer jojoba oil exhibited the most favorable drug loading and release features. The TEs combined with the CRG-PVP hydrogels (nanogels) successfully improve NIA skin deposition with reduced permeation $\left(1.17 \pm 0.17 \times 10^{-5} \mathrm{~cm} / \mathrm{s}\right.$ in comparison to $3.01 \pm 0.66 \times 10^{-5} \mathrm{~cm} / \mathrm{s}$, obtained for hydrogels without TEs). Some drug delivery systems have already been designed for NIA's skin delivery, namely liposomes, solid lipid nanoparticles, and even microneedles. These focus on the improvement of skin permeability, while here the hybrid nanogels aim to retain NIA in the skin with low systemic distribution, as evidenced by the skin permeation data. These advantages from the hybrid nanogels will allow for further applications aiming a local action of the drug. Yet, more research is needed to improve the drug loading and storage stability of the TEs. In vitro photoprotection to UVB radiation in human keratinocytes was observed for the treatment of empty nanogels and NIA-loaded nanogels, indicating a possible synergistic effect of the TEs composition and NIA. The evaluation of the developed hybrid nanogels in human skin could be further pursue given their biocompatible properties and the promising delivery of NIA. Overall, the new nanogel can be further applied in sunscreens or cosmetic products to improve skin protection towards photo-aging, skin inflammation and even pre-cancerous skin lesions.

Supplementary Materials: The following are available online at https:/ / www.mdpi.com/article/10 $.3390 /$ pharmaceutics13111968/s1, Figure S1: Photograph of one of the optimized hydrogel combinations (CRG-PVP $(1: 1)+$ NIA 1\% $(w / w)+$ jojoba oil 5\%); Figure S2: Evaluation of jojoba oil effect on NIA-loaded hydrogel's chemical nature through FTIR; Figure S3: Storage stability of NIA-loaded formulations at $4{ }^{\circ} \mathrm{C}$ over 2 weeks. Size, zeta potential, and polydispersity index values displayed 
(Size: SD < 2\%; ZP: SD < 5\%; PDI: SD < 3\%); Figure S4: Storage stability of NIA-loaded formulations at $4{ }^{\circ} \mathrm{C}$ over 8 weeks. EE\% and LC\% values displayed; Figure S5: In vitro skin permeation results of free NIA and NIA-loaded developed hydrogels from four independent experiments $(n=4)$. Asterisks indicate statistical significance $\left({ }^{*}, p \leq 0.05 ;{ }^{* *}, p \leq 0.01 ;{ }^{* * *}, p \leq 0.001 ; * * * *, p \leq 0.0001\right)$. No asterisks indicate no statistical significance ( $p>0.05)$; Table S1: Characterization of non-loaded TEs TE tween 80 , oleic acid and jojoba oil.

Author Contributions: Conceptualization, C.N. and S.A.C.L.; methodology, R.B. and R.A.; validation, C.N. and S.A.C.L.; formal analysis, R.A. and R.B.; investigation, R.A. and R.B.; resources, S.R.; writing—original draft preparation, R.B.; writing—review and editing, R.A., C.N., S.A.C.L. and S.R.; supervision, C.N. and S.A.C.L.; project administration, S.R.; funding acquisition, S.A.C.L. All authors have read and agreed to the published version of the manuscript.

Funding: This work received financial support from the European Union (FEDER funds through COMPETE POCI-01-0145-FEDER-030834) and the National Funds (FCT, Fundação para a Ciência e Tecnologia) through project PTDC/QUI-COL/30834/2017.

Institutional Review Board Statement: Not applicable.

Informed Consent Statement: Not applicable.

Data Availability Statement: On request.

Acknowledgments: The work was also supported through the project UIDB/50006/2020 । UIDP/50006/2020, funded by FCT/MCTES through the National Funds. RB and RA thank their funding from this project. CN and SACL thank funding from FCT/MEC (IF/00293/2015 and CEECIND/01620/2017, respectively) financed by the National Funds.

Conflicts of Interest: The authors declare no conflict of interest.

\section{References}

1. Ruela, A.L.M.; Perissinato, A.G.; Lino, M.E.D.S.; Mudrik, P.S.; Pereira, G.R. Evaluation of skin absorption of drugs from topical and transdermal formulations. Braz. J. Pharm. Sci. 2016, 52, 527-544. [CrossRef]

2. Homayun, B.; Lin, X.; Choi, H.J. Challenges and recent progress in oral drug delivery systems for biopharmaceuticals. Pharmaceutics 2019, 11, 129. [CrossRef]

3. Bardal, S.K.; Waechter, J.E.; Martin, D.S. Pharmacokinetics. In Applied Pharmacology; Elsevier Health Sciences: Amsterdam, The Netherlands, 2011; pp. 17-34.

4. Venkata, V.; Reddy, S. Importance of Selecting Route of Administration in Designing Products for Diabetic Foot Ulcers. J. Pharm. Pharm. 2015, 2, 20-21. [CrossRef]

5. Hua, S. Lipid-based nano-delivery systems for skin delivery of drugs and bioactives. Front. Pharmacol. 2015, 6, 219. [CrossRef] [PubMed]

6. Offerta, A.; Bonina, F.; Gasparri, F.; Zanardi, A.; Micicchè, L.; Puglia, C. In vitro Percutaneous Absorption of Niacinamide and Phytosterols and in vivo Evaluation of their Effect on Skin Barrier Recovery. Curr. Drug Deliv. 2016, 13, 111-120. [CrossRef]

7. Thomas, S.; Bharti, A.; Tharpa, K.; Agarwal, A. Quantification of potential impurities by a stability indicating UV-HPLC method in niacinamide active pharmaceutical ingredient. J. Pharm. Biomed. Anal. 2012, 60, 86-90. [CrossRef] [PubMed]

8. Chen, A.C.; Damian, D.L. Nicotinamide and the skin. Australas. J. Dermatol. 2014, 55, 169-175. [CrossRef]

9. Fang, E.F.; Hou, Y.; Demarest, T.G.; Croteau, D.L.; Mattson, M.P.; Bohr, V.A. NAD ${ }^{+}$in Aging: Molecular Mechanisms and Translational Implications. Trends Mol. Med. 2017, 23, 899-916. [CrossRef]

10. Gehring, W. Nicotinic acid / niacinamide and the skin. J. Cosmet. Dermatol. 2004, 3, 88-93. [CrossRef]

11. Bissett, D.L. Common cosmeceuticals. Clin. Dermatol. 2009, 27, 435-445. [CrossRef]

12. Menon, G.K.; Cleary, G.W.; Lane, M.E. The structure and function of the stratum corneum. Int. J. Pharm. 2012, 435, 3-9. [CrossRef]

13. Alkilani, A.Z.; McCrudden, M.T.C.; Donnelly, R.F. Transdermal drug delivery: Innovative pharmaceutical developments based on disruption of the barrier properties of the stratum corneum. Pharmaceutics 2015, 7, 438-470. [CrossRef]

14. Larrañeta, E.; Lutton, R.E.M.; Woolfson, A.D.; Donnelly, R.F. Microneedle arrays as transdermal and intradermal drug delivery systems: Materials science, manufacture and commercial development. Mater. Sci. Eng. R Rep. 2016, 104, 1-32. [CrossRef]

15. N'Da, D.D. Prodrug strategies for enhancing the percutaneous absorption of drugs. Molecules 2014, 19, 20780-20807. [CrossRef] [PubMed]

16. Chmiel, T.; Mieszkowska, A.; Kempińska-Kupczyk, D.; Kot-Wasik, A.; Namieśnik, J.; Mazerska, Z. The impact of lipophilicity on environmental processes, drug delivery and bioavailability of food components. Microchem. J. 2019, 146, 393-406. [CrossRef]

17. PubChem Compound Summary for CID 936, Nicotinamide. Available online: https://pubchem.ncbi.nlm.nih.gov/compound/ Nicotinamide. (accessed on 3 January 2021). 
18. Lee, M.H.; Lee, K.K.; Park, M.H.; Hyun, S.S.; Kahn, S.Y.; Joo, K.S.; Kang, H.C.; Kwon, W.T. In vivo anti-melanogenesis activity and in vitro skin permeability of niacinamide-loaded flexible liposomes (Bounsphere ${ }^{\mathrm{TM}}$ ). J. Drug Deliv. Sci. Technol. 2016, 31, 147-152. [CrossRef]

19. Shin, C.I.; Kim, M.; Kim, Y.C. Delivery of niacinamide to the skin using microneedle-like particles. Pharmaceutics 2019, 11, 326. [CrossRef] [PubMed]

20. Chai, Q.; Jiao, Y.; Yu, X. Hydrogels for Biomedical Applications: Their Characteristics and the Mechanisms behind Them. Gels 2017, 3, 6. [CrossRef] [PubMed]

21. Zhang, Y.; Ye, L.; Cui, M.; Yang, B.; Li, J.; Sun, H.; Yao, F. Physically crosslinked poly(vinyl alcohol)-carrageenan composite hydrogels: Pore structure stability and cell adhesive ability. R. Soc. Chem. Adv. 2015, 5, 78180-78191. [CrossRef]

22. Ghasemiyeh, P.; Samani, S.M. Hydrogels as Drug Delivery Systems; Pros and Cons (Review Article). Trends Pharm. Sci. 2019, 5 , 7-24. [CrossRef]

23. Frias, A.M.; Carida, M.; Cancedda, R.; Gomes, M.E.; Mano, F.; Reis, R.L. Carrageenan-Based Hydrogels for the Controlled Delivery of PDGF-BB in Bone Tissue Engineering Applications. Biomacromolecules 2009, 10, 1392-1401. [CrossRef]

24. Akalin, G.O.; Pulat, M. Preparation and characterization of $\mathrm{k}$-carrageenan hydrogel for controlled release of copper and manganese micronutrients. Polym. Bull. 2020, 77, 1359-1375. [CrossRef]

25. Mihaila, S.M.; Gaharwar, A.K.; Reis, R.L.; Marques, A.P.; Gomes, M.E.; Khademhosseini, A. Photocrosslinkable kappa-carrageenan hydrogels for tissue engineering applications. Adv. Healthc. Mater. 2013, 2, 895-907. [CrossRef] [PubMed]

26. Mangione, M.R.; Giacomazza, D.; Bulone, D.; Martorana, V.; Cavallaro, G.; San Biagio, P.L. K + and Na + effects on the gelation properties of K-Carrageenan. Biophys. Chem. 2005, 113, 129-135. [CrossRef] [PubMed]

27. Sadasivuni, K.K. A Comparative Review of Natural and Synthetic Biopolymer Composite Scaffolds. Polymers 2021, 13, 1105. [CrossRef]

28. Franco, P.; De Marco, I. The use of poly(N-vinyl pyrrolidone) in the delivery of drugs: A review. Polymers 2020, $12,1114$. [CrossRef] [PubMed]

29. Hoare, T.R.; Kohane, D.S. Hydrogels in drug delivery: Progress and challenges. Polymer 2008, 49, 1993-2007. [CrossRef]

30. Esmaeely Neisiany, R.; Enayati, M.S.; Sajkiewicz, P.; Pahlevanneshan, Z.; Ramakrishna, S. Insight Into the Current Directions in Functionalized Nanocomposite Hydrogels. Front. Mater. 2020, 7, 25. [CrossRef]

31. Jiang, Y.; Krishnan, N.; Heo, J.; Fang, R.H.; Zhang, L. Nanoparticle-hydrogel superstructures for biomedical applications. J. Control. Release 2020, 324, 505-521. [CrossRef]

32. Zhang, H.; Zhu, Y.; Qu, L.; Wu, H.; Kong, H.; Yang, Z.; Chen, D.; Mäkilä, E.; Salonen, J.; Santos, H.A.; et al. Gold Nanorods Conjugated Porous Silicon Nanoparticles Encapsulated in Calcium Alginate Nano Hydrogels Using Microemulsion Templates. Nano Lett. 2018, 18, 1448-1453. [CrossRef]

33. Jiang, T.; Wang, T.; Li, T.; Ma, Y.; Shen, S.; He, B.; Mo, R. Enhanced Transdermal Drug Delivery by Transfersome-Embedded Oligopeptide Hydrogel for Topical Chemotherapy of Melanoma. ACS Nano 2018, 12, 9693-9701. [CrossRef]

34. Jøraholmen, M.W.; Johannessen, M.; Gravningen, K.; Puolakkainen, M.; Acharya, G.; Basnet, P.; Škalko-Basnet, N. Liposomes-inhydrogel delivery system enhances the potential of resveratrol in combating vaginal chlamydia infection. Pharmaceutics 2020, 12, 1203. [CrossRef] [PubMed]

35. Song, C.K.; Balakrishnan, P.; Shim, C.; Chung, S.; Chong, S.; Kim, D. A novel vesicular carrier, transethosome, for enhanced skin delivery of voriconazole: Characterization and in vitro/in vivo evaluation. Colloids Surf. B Biointerfaces 2012, 92, 299-304. [CrossRef]

36. Mishra, K.K.; Kaur, C.D.; Verma, S.; Sahu, A.K.; Dash, D.K.; Kashyap, P.; Mishra, S.P. Transethosomes and Nanoethosomes: Recent Approach on Transdermal Drug Delivery System. Nanomedicine 2019, 2, 33-54.

37. Moolakkadath, T.; Aqil, M.; Ahad, A.; Imam, S.S.; Sultana, Y.; Mujeeb, M.; Iqbal, Z. Development of transethosomes formulation for dermal fisetin delivery: Box-Behnken design, optimization, in vitro skin penetration, vesicles-Skin interaction and dermatokinetic studies. Artif. Cells Nanomed. Biotechnol. 2018, 46, S755-S765. [CrossRef] [PubMed]

38. Abdelbary, A.A.; Refai, H. Use of transethosomes for enhancing the transdermal delivery of olmesartan medoxomil: In vitro, ex vivo, and in vivo evaluation. Int. J. Nanomed. 2019, 14, 1953-1968. [CrossRef]

39. Shaji, J.; Bajaj, R. Transethosomes: A new prospect for enhanced transdermal delivery. Int. J. Pharm. Sci. Res. 2018, 9, 2681-2685. [CrossRef]

40. Kumar, L.; Verma, S.; Aktuelno, T.T.; Singh, K.; Prasad, D.N. Ethanol Based Vesicular Carriers in Transdermal Drug Delivery: Nanoethosomes and Transethosomes in Focus. NanoWorld J. 2016, 2, 41-51. [CrossRef]

41. Sala, M.; Diab, R.; Elaissari, A.; Fessi, H. Lipid nanocarriers as skin drug delivery systems: Properties, mechanisms of skin interactions and medical applications. Int. J. Pharm. 2018, 535, 1-17. [CrossRef] [PubMed]

42. Apsara, S.; Opatha, T.; Titapiwatanakun, V.; Chutoprapat, R. Transfersomes: A Promising Nanoencapsulation Technique for Transdermal Drug Delivery. Pharmaceutics 2020, 12, 855. [CrossRef]

43. Smith, G. European medicines agency guideline on bioanalytical method validation: What more is there to say? Bioanalysis 2012, 4, 865-868. [CrossRef] [PubMed]

44. Lee, S.H.; Jeong, S.K.; Ahn, S.K. An update of the defensive barrier function of skin. Yonsei Med. J. 2006, 47, 293-306. [CrossRef] [PubMed] 
45. Aggarwal, G.; Dhawan, S.; HariKumar, S.L. Natural Oils as Skin Permeation Enhancers for Transdermal Delivery of Olanzapine: In Vitro and In Vivo Evaluation. Curr. Drug Deliv. 2012, 9, 172-181. [CrossRef] [PubMed]

46. Yacob, N.; Hashim, K. Morphological effect on swelling behaviour of hydrogel. AIP Conf. Proc. 2014, 1584, 153-159. [CrossRef]

47. Arockia Mary, I.; Selvanayagam, S.; Selvasekarapandian, S.; Srikumar, S.R.; Ponraj, T.; Moniha, V. Lithium ion conducting membrane based on K-carrageenan complexed with lithium bromide and its electrochemical applications. Ionics 2019, 25, 5839-5855. [CrossRef]

48. Rahma, A.; Munir, M.M.; Khairurrijal; Prasetyo, A.; Suendo, V.; Rachmawati, H. Intermolecular Interactions and the Release Pattern of Electrospun Curcumin-Polyvinyl(pyrrolidone) Fiber. Biol. Pharm. Bull. 2016, 39, 163-173. [CrossRef] [PubMed]

49. Erizal, E.; Tjahyono, T.; Perkasa, D.P.; Darwis, D. Synthesis of Polyvinyl Pirrolidone (PVC) /K-Carrageenan Hydrogel Prepared by Gamma Radiation Processing As a Function of Dose and PVP Concentration. Indones. J. Chem. 2013, 13, 41-46. [CrossRef]

50. Bayarı, S.; Atac, A. Coordination behaviour of nicotinamide: An infrared spectroscopic study. J. Mol. Struct. 2003, 655, 163-170. [CrossRef]

51. Jenning, V.; Gysler, A.; Schäfer-Korting, M.; Gohla, S.H. Vitamin A loaded solid lipid nanoparticles for topical use: Occlusive properties and drug targeting to the upper skin. Eur. J. Pharm. Biopharm. 2000, 49, 211-218. [CrossRef]

52. Danaei, M.; Dehghankhold, M.; Ataei, S.; Hasanzadeh Davarani, F.; Javanmard, R.; Dokhani, A.; Khorasani, S.; Mozafari, M.R. Impact of particle size and polydispersity index on the clinical applications of lipidic nanocarrier systems. Pharmaceutics 2018, 10, 57. [CrossRef]

53. Upadhyay, S.U.; Patel, J.K.; Patel, V.A.; Saluja, A.K. Effect of different lipids and surfactants on formulation of solid lipid nanoparticles incorporating tamoxifen citrate. J. Pharm. Bioallied Sci. 2012, 4, 112-113. [CrossRef]

54. Sis, H.; Birinci, M. Effect of nonionic and ionic surfactants on zeta potential and dispersion properties of carbon black powders. Colloids Surf. A Physicochem. Eng. Asp. 2009, 341, 60-67. [CrossRef]

55. Almgren, M.; Edwards, K. Cryo transmission electron microscopy of liposomes and related structures. Physicochem. Eng. Asp. 2008, 174, 3-21. [CrossRef]

56. Ascenso, A.; Raposo, S.; Batista, C.; Cardoso, P.; Mendes, T.; Praça, F.G.; Bentley, M.V.L.B.; Simões, S. Development, characterization, and skin delivery studies of related ultradeformable vesicles: Transfersomes, ethosomes, and transethosomes. Int. J. Nanomed. 2015, 10, 5837-5851. [CrossRef]

57. Iliopoulos, F.; Sil, B.C.; Monjur Al Hossain, A.S.M.; Moore, D.J.; Lucas, R.A.; Lane, M.E. Topical delivery of niacinamide: Influence of neat solvents. Int. J. Pharm. 2020, 579. [CrossRef]

58. Zhang, Y.; Lane, M.E.; Moore, D.J. An investigation of the influence of PEG 400 and PEG-6-caprylic/capric glycerides on dermal delivery of niacinamide. Polymers 2020, 12, 2907. [CrossRef] [PubMed]

59. Sun, X.; Kim, A.; Nakatani, M.; Shen, Y.; Liu, L. Distinctive molecular responses to ultraviolet radiation between keratinocytes and melanocytes. Exp. Dermatol. 2016, 25, 708-713. [CrossRef] [PubMed]

60. Zhen, A.X.; Piao, M.J.; Kang, K.A.; Fernando, P.D.S.M.; Kang, H.K.; Koh, Y.S.; Yi, J.M.; Hyun, J.W. Niacinamide protects skin cells from oxidative stress induced by particulate matter. Biomol. Ther. 2019, 27, 562-569. [CrossRef] [PubMed]

61. Rodriguez-Luna, A.; Ávila-Román, J.; Oliveira, H.; Motilva, V.; Talero, E. Fucoxanthin and Rosmarinic Acid Combination Has Anti-Inflammatory E ff ects through Regulation of. Mar Drugs 2019, 17, 451. [CrossRef]

62. Damian, D.L. Photoprotective effects of nicotinamide. Photochem. Photobiol. Sci. 2010, 9, 578-585. [CrossRef] 